\title{
Re-scaling risk governance using local appraisal and community involvement
}

\author{
Alexandre Oliveira Tavares ${ }^{\mathrm{a} *}$ and Pedro Pinto dos Santos ${ }^{\mathrm{b}}$ \\ ${ }^{a}$ Centre for Social Studies and Earth Sciences Department of the University of Coimbra, \\ Coimbra, Portugal; ${ }^{b}$ Centre for Social Studies of the University of Coimbra, Coimbra, \\ Portugal
}

(Received 14 February 2013; final version received 13 June 2013)

\begin{abstract}
This paper describes a risk governance model applied on a local scale, showing the advantages and constraints found during its application. The risk governance model, built on a municipal scale, results from the application of the International Risk Governance Council framework. The model is characterised by the cyclicity between the assessment and management spheres, assuming communication to be essential in all stages. Its application in central Portugal is rooted in a specific knowledge of hazards and their impacts, the human and financial constraints, and the expectations of citizens and stakeholders. The results show that preformatted management solutions derived from national civil protection stakeholders can be adapted to a local physical, social and institutional context. It was found that this depends significantly on the stakeholders' concerns assessment, as this allows the subsequent risk management options to be adapted and legitimised. As a result, more appropriate land-use regulations and mitigation strategies are being designed, which are related to urban planning, road design, risk sensitisation and communication tools. However, two features are likely to lead to an overlapping of competences and conflicts concerning responsibility for decision-making in the actual civil protection structure: the current constraints on resources on an operational level and the potentially inadequate representation of stakeholders on a strategic level.
\end{abstract}

Keywords: risk governance; municipal level; appraisal; communication; emergency planning

\section{Introduction}

The risk society, characterised by greater individual and collective awareness of potential dangers, has meant that citizens, technicians, scientists and political agents have become increasingly organised around the challenge of risk governance (Kasperson, Kasperson, and Dow 2001). As pointed out by Beck (1992), citizens and stakeholders are always exposed to risk and present competing and conflicting objectives, interests and viewpoints associated with their perceptions and previous experience. The interaction between stakeholders who produce knowledge and those who use it, and the creation of institutional contexts that generate a deeper understanding of each others' needs and constraints (Weichselgartner and Kasperson 2010), should be one of the aims of risk governance.

*Corresponding author. Email: atavares@ci.uc.pt 
According to Fischer (2003), risk management can be addressed in two dimensions: the scale for estimating severity and the degree of disturbance produced in the community. This relationship is consistent with the multiscale vision discussed by Handmer and Dovers (2007) and Fekete, Damm, and Birkmann (2010), in which disasters generate temporal and spatial scale impacts and determine irreversible political decisions, but also represent an opportunity to learn from local assets and experiences (Voss and Wagner 2010).

As Aven and Renn (2010) emphasise, risk management incorporates a plurality of forms of knowledge and values in terms of levels of participation and decisionmaking. These should be supported by the general involvement of stakeholders and citizens, establishing logical judgements that extend beyond technical and scientific knowledge.

The focus of this research is risk governance, which frames both the institutional structure and the policy process that guides and restricts collective activities (Pelling et al. 2008; Klinke and Renn 2012). The main task is to describe a risk governance model applied on a local scale, showing the advantages and constraints found during its application.

The analysis extends from initial pre-assessment to decision-making, involving procedural mechanisms, institutional commitments and citizen and stakeholder involvement in risk governance on a local level. The risk framework includes the natural and technological hazards that can be managed and planned on a municipal level. The risks and strategies that did not fit into this scale were eliminated and are not represented in the municipal emergency planning regulatory principles. A cyclic model was developed to address hazards and concerns assessment, institutional, instrumental and regulatory functionality and emergency planning. In the terms defined by Adger (2000), a model was built that linked institutions and their resources to the ability of groups or communities to cope with external stresses and disturbances.

The following contextualisation of the theme and the example constructed both aim to improve on studies which offer a holistic approach to local risk governance models.

\section{The contextualisation approach}

An understanding of the geographical context of risk - the interaction between potential hazards and vulnerability (Cutter, Boruff, and Shirley 2003; Greiving, Fleischhauer, and Luckenkotter 2006) - is fundamental to organised and effective risk management (Sapountzaki et al. 2011).

The adaptive and integrated governance of risk requires a set of resources that involve pre-assessment, appraisal and risk management, in which communication and stakeholder participation play a decisive role (Klinke and Renn 2012). These focuses form the basis of substantial discussion of the territorial and institutional frameworks by the stakeholders in question, as well as the legitimation of decisionmaking (Corfee-Morlot et al. 2011).

Recent frameworks indicate the importance of risk management as part of the responsibilities of local government (Bhattamishra and Barrett 2010), since local administrators are able to move beyond mitigation to include a focus on adaptation in practical terms and enable changes to be made to planning frameworks (Measham et al. 2011). The emphasis on local risk assessment and management 
policies (Somers and Svara 2009; Henstra 2010) emerges from recognition of the relevance of the impacts of hazardous processes and their potential economic and political implications. Moreover, as noted by Palm and Ramsell (2007), their effectiveness is strengthened by inter-municipal cooperation and coordination.

In general, the regulations for preventing and reducing the natural and technological aspects of risk are defined in regional, national or super-national conceptual frameworks and strategies supported by large-scale territories, which use standardised management tools and depend on economic resources concentrated in non-local levels of governance (Kasperson, Kasperson, and Dow 2001; Birkmann 2007). The application of top-down risk management directives (Tavares and Mendes 2010), frequently imposing methodological approaches that must be implemented using municipal resources and subsequently validated at a higher administrative level, stresses the importance of cross-scale and cross-level interactions, as highlighted by Cash et al. (2006).

The relevance of selecting a valid spatial unit of analysis for risk decision-making applicable on a local level, with spatial orientation, is a challenge that has been identified by Chen, Blong, and Jacobson (2003), Apel et al. (2009) and Fekete, Damm, and Birkmann (2010).

Several studies stress the importance of the local administration in assessing risk, and conflicting interests and focuses (Flez and Lahousse 2004; Henstra 2010; Liu et al. 2011; Measham et al. 2011; Sapountzaki et al. 2011). Local administrators, who are generally responsible for planning, must have an integrated vision of risk management rather than focusing on emergency management since, for citizens and professional bodies, balanced commitment is the key to reducing tensions between different interests. Unlike risk management prevention and reduction measures, the emergency response traditionally follows a bottom-up approach (Waugh 1996; Somers and Svara 2009) in which local government agencies are expected to plan for and mitigate risk, and provide a variety of first responder services which are not always comprehensible to citizens and are subject to poor quality control (Moar 2010).

A number of trigger factors can be identified which explain the weakness of local risk management and the ineffective dissemination of emergency management procedures: the low perception of risk, inadequate human and material emergency resources, the low recognition and status of emergency agents, and the lack of emergency management skills and training.

Risk communication has progressively evolved from providing simple information for citizens and stakeholders (Gray, Stern, and Biocca 1998) to building frameworks in which they become involved in the decision-making process (Renn 2006; Schmidt-Thomé and Schmidt-Thomé 2007; Höppner, Buchecker, and Bründl 2010; Aven and Renn 2010). However, as noted by Veil, Littlefield, and Rowan (2009), there are some recurring constraints, in particular the assumption of a narrow-based communications process. Nevertheless, as pointed out by Sapountzaki and others (2011), the benefits of communication will not only improve coordination between civil protection and spatial planning but also the understanding of public policies and their ability to mitigate risks.

In the International Risk Governance Council model (IRGC 2005), the importance of communication and consultancy is emphasised at every stage in the assessment and management process. Given the cyclicity that characterises the risk governance model, other actions should be planned as part of the updated risk 
appraisal framework. Four stages are conceptualised for the risk governance cycle (Figure 1), namely pre-assessment, risk appraisal, risk judgement - based on the previous risk and concerns assessment - and risk management.

This framework for risk governance is based on continuous multilevel communication, not only in order to disseminate information but also to foster interaction and the exchange of information between stakeholders. The focus on communication requires a set of available resources and a stakeholder involvement strategy (Klinke and Renn 2012) with a platform that should be comprehensive and community based.

This paper aims to build a local governance model, from the pre-assessment to the emergency planning and decision-making stages, which is centred on communication and citizen and stakeholder involvement. The municipal example presented aims to address the following:

- Building spatial risk management outputs based on local evidence, using a bottom-up approach;

- Citizen recognition and stakeholder understanding of risk appraisal and emergency planning;

- Building bridges at local risk governance level, involving emergency managers and planners; and

- Designing a local community-based risk communication strategy as a dissemination process.

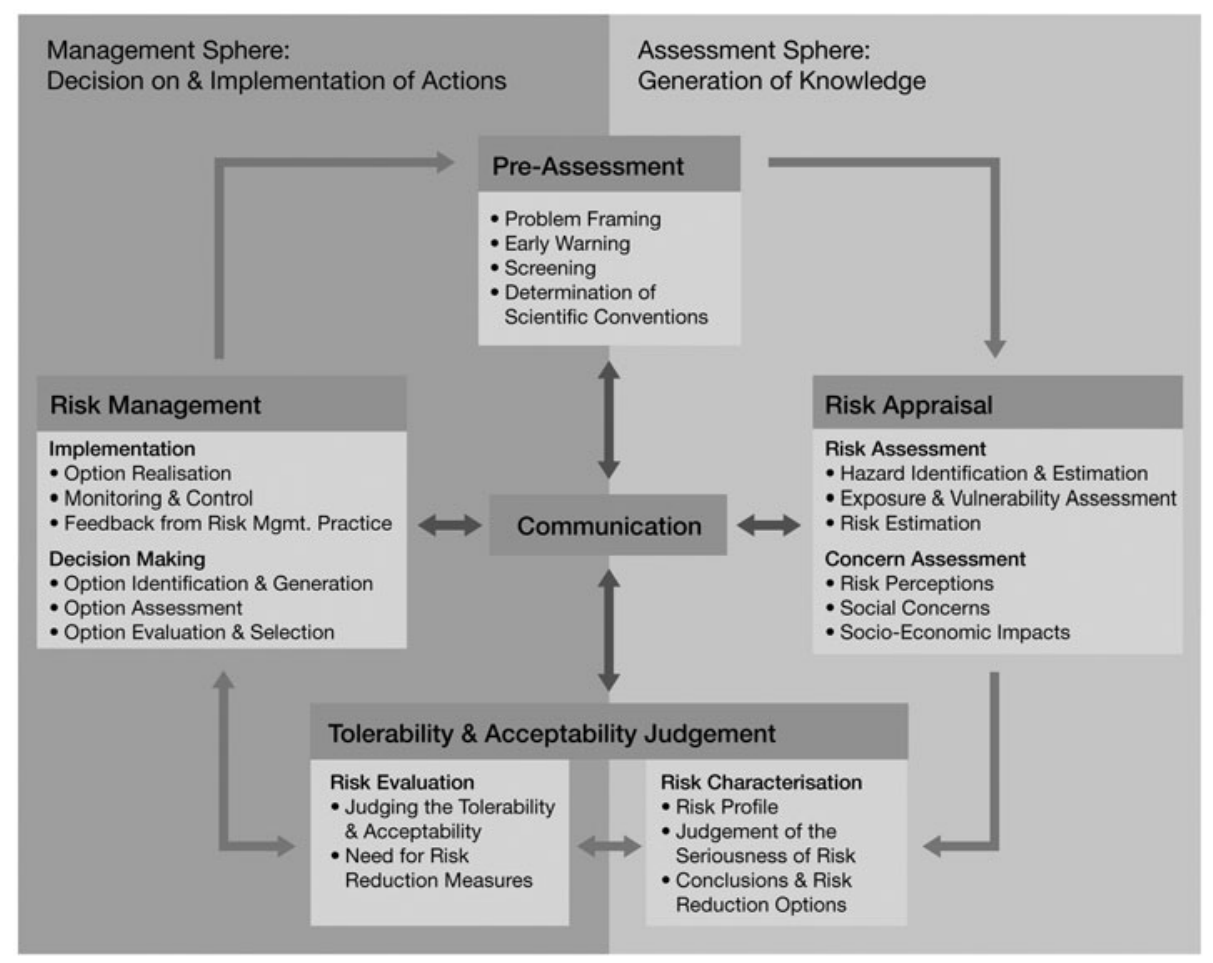

Figure 1. The IRGC risk governance model (IRGC 2005). 


\section{The local risk governance context}

As argued by Mendes and Tavares (2008), the need to reconcile scientific knowledge with technical instruments in Portugal has emerged parallel to the inclusion of experiences and practices in risk management measures, allowing risk management instruments to be linked to tools for regional planning, with the involvement of the stakeholders concerned. The risk framework is supported by top-down polices associated with planning policies, namely the National Spatial Policy Programme for Planning Policies (Law 58/2007), the Coastal Management Framework (Resolution of the Council of Ministers 82/2009), the EU Directive on assessment and management of flood risks (Directive 2007/60/ EC) and the National Ecological Protection Regime (Decree 166/2008). Likewise, emergency civil protection is also framed by the Base Law for Civil Protection (Law 27/2006), an instrument designed to coordinate the operational relief system (Decree 134/2006) and the National System for Forest Fire Defence (Decree 124/2006).

As noted by Tavares (2010), it therefore makes sense to discuss the nature of the involvement of the various stakeholders in the risk assessment process, acknowledging the specificities and promoting mutual trust, cooperation and involvement in decision-making, This is supported by the importance of instruments such as the Municipal Master Plans (in accordance with Decree 316/2007) and the Municipal Civil Protection and Emergency Plans (Law 65/2007) in the application of risk prevention, reduction and mitigation policies and instruments.

In an attempt to bridge the gaps and develop comprehensive local polices using a holistic approach to risk management, an intensive project was developed involving academics and a local municipality, and focusing on community-based communication.

The chosen municipality was Alvaiázere (Figure 2) in the district of Leiria (Central Portugal), which has rural characteristics, low-population density, inadequate infrastructures and low levels of welfare. The municipality has an area of $159.96 \mathrm{~km}^{2}$ and had a population of 7287 inhabitants in 2011, a decrease of $13.6 \%$ in comparison with the total population in 2001 (8438 inhabitants). The population is elderly - according to the 2011 population census $32.8 \%$ of the residents were over 64 years old and $10.8 \%$ under 15 years old. The study area has contrasting morphological characteristics. The eastern sector has steeper slopes and incised streams, whereas the western sector consists of hills that create an undulating landscape in which the limestone Alvaiázere mountain, standing $618 \mathrm{~m}$ high, is the outstanding feature. The municipality is composed of seven parishes and the settlements are mainly located near, or along, the main road infrastructure, National Road 110, which crosses the municipal territory from N-S. The major urban areas are the villages of Alvaiázere, Cabaços (near Pussos) and Maçãs de Dona Maria. The main land uses are forestry, natural landscape and farmlands. The economy is based mainly on the primary sector - mining, olive groves, vineyards and forest production, with large patches of pine and eucalyptus. The municipality has experienced a series of natural and technological events that have had a significant social and economic impact, and was looking for a means of rescaling the risk management focus that would involve changes to institutional and organisational processes and also to communication and involvement of citizens and stakeholders. 


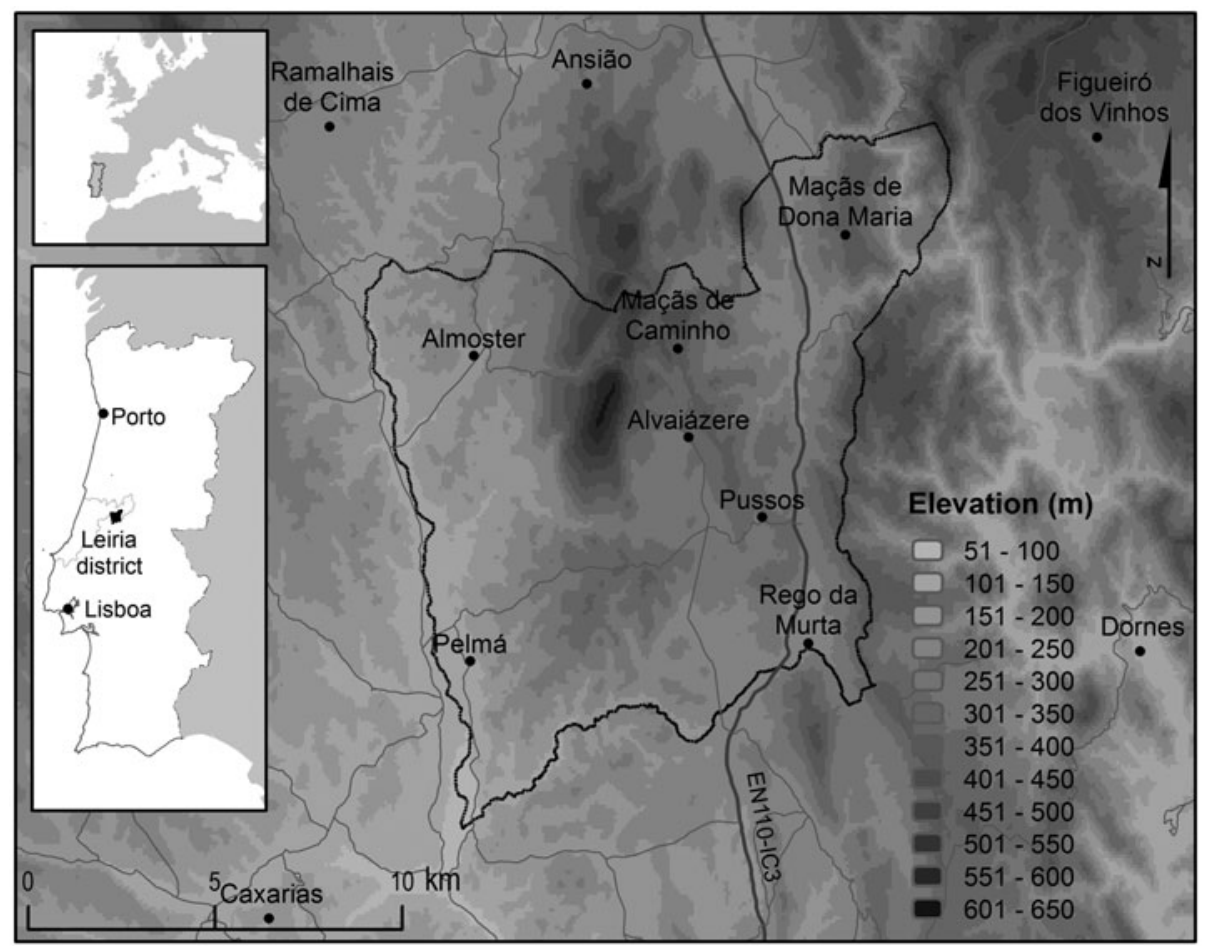

Figure 2. Geographical context of the municipality of Alvaiázere, showing the seven parishes.

\section{Methods}

The risk governance model is based on the (IRGC 2005), characterised by the cyclicity of the stages, from assessment to management. This model has some similarities to the Australian emergency risk management approach (EMA 2004). The decision-making process involved local stakeholders and the municipality's strong commitment to serving as the main promoter of governance processes. The framework was built up on the basis of direct consultation with the local authorities and technicians, and the expertise of the University of Coimbra, Portugal. The university also acted as a communications facilitator between the promoter and other private and public stakeholders. This interaction contributed to the pre-assessment stage in which the local risk governance problem was framed, the screening options that were designed, and the scientific and technical conceptual links established.

As defined in the IRGC (2005), the communication strategy is understood in its broadest sense, including the involvement of the different stakeholders and the public, as well as risk communication itself. In brief, the working model was developed in the following stages:

- Risk appraisal, including hazard data collection and territorial characterisation, risk perception and stakeholder concerns;

- Risk characterisation, involving the identification and classification of the relevant hazardous processes and the evaluation and mapping of risk components; 
- Judgement of the hazardous processes for risk management and political engagement; evaluation of resources and territorial capabilities for risk management;

- Design and implementation of the emergency planning framework for risk management;

- Decision-making involving emergency planning support and coordination, public communication and governance reassessment.

\subsection{Risk appraisal}

Risk appraisal comprises gathering data on two aspects of risk: technical/scientific knowledge, and the perceptions and concerns of public and private stakeholders. Sequentially, both analyses were undertaken in the following way.

The acquisition and analysis of geographical data included the collection, integration and analysis, in a GIS environment, of data on the territory's morphology, geology, hydrology, climatology, land use, urban typology and demography. Historical data on damage and loss were collected from the Leiria District Command for Civil Protection Operations (CDOS-Leiria), local security forces (Guarda Nacional Republicana) and the municipal fire department statistical databases. The local newspaper ' $\mathrm{O}$ Alvaiazerense' was searched for the period ranging from January 1999 to March 2010 to collect additional data on hazardous events. Some historical evidence - relating in particular to natural hazards - was interpreted using fieldwork and remote-sensing tools applied to base cartography on different scales and aerial photography. The base cartography on a scale of 1:2000 (available for the area surrounding the Alvaiázere village) and 1:10.000 (for the remaining area in the municipality) was used to produce the digital terrain models (DTM) applied in the susceptibility models. 1:25.000 maps and aerial photography on a scale of 1:15.000 - as well as the products extracted from the DTM - were used to identify past evidence of hazardous processes. The GIS and statistics software used included ArcGIS 9.3 ${ }^{\odot}$ and IBM SPSS Statistics $19^{\odot}$.

The evaluation of risk perception and stakeholder concerns was crucial in the risk appraisal stage. Concerns assessment involved the use of a structured survey focusing on the stakeholders' local knowledge of previous hazardous events, and the related damage and losses. A total of 24 guided interviews were conducted in the seven parishes in the municipality and also administered to the relevant civil protection stakeholders, including the fire department commander, the municipal health delegate and the head of municipal civil protection. In each parish, interviews were held with the political leader and residents with substantial local knowledge. The evaluation used the official Portuguese guide for municipal risk assessment and mapping (Julião et al. 2009), which describes the list of potential natural and technological hazards to be considered in Portugal.

\subsection{Risk characterisation}

This stage began with the identification and classification of the relevant hazardous processes, proposing a hierarchy according to severity of damage and probability of occurrence. Previous risk appraisal assets allowed for an informed selection of the 11 main hazardous processes (Table 1) affecting the municipality. Out of the items 
on the list, only accidents with farm and forestry machinery are not considered in the aforementioned municipal guide (Julião et al. 2009), which is acceptable. Nevertheless, the statistical and press data, as well as oral interviews, substantiate their inclusion as one of the main hazardous processes causing fatalities and permanent disability each year.

Risk classification was based on the application of two risk matrices. Although in different ways, both combine likelihood and consequence. The first was the risk matrix proposed by the Portuguese National Authority for Civil Protection (ANPC 2009), based on IDEHLG (2006), which cross-references five classes of probability with five classes of severity according to the criteria established. The highest class of probability is attributed to hazardous processes that are expected to occur at least once a year. In terms of severity, the classification is based on the registered effects on the population, the natural environment and the economy, attributing the highest class to the effects which ranked highest in each of these three components. The final risk classes are 'low', 'moderate', 'high' and 'extreme'. The other matrix used was the Hazard Analysis Matrix (OEM-HAM) proposed by the Oregon Emergency Management (OEM 2008). The OEM-HAM provides a good risk ranking tool, based on a method which considers four components that characterise risk: history $(\mathrm{H})$, vulnerability $(\mathrm{V})$, maximum threat $(\mathrm{MT})$ and probability $(\mathrm{P})$. Each is assigned a severity rating ranging from 1 to 10 according to the following classification: low (1-3), medium (4-7) and high (8-10). OEM-HAM assigns a weight factor (WF) to each component (see Equation (1)) and reaches a total score (TS) for each hazardous process as follows, which can vary from 24 to 240 :

$$
\mathrm{TS}=(H \times 2)+(V \times 5)+(\mathrm{MT} \times 10)+(P \times 7)
$$

The next step consisted of mapping the risk components following the methodological guide to risk mapping at municipal level (Julião et al. 2009), which

Table 1. Initial and selected list of the considered hazardous processes considered.

\begin{tabular}{lll}
\hline & Previously considered in the survey & Selected \\
\hline Natural & $\begin{array}{l}\text { Cold waves, drought, earthquakes, } \\
\text { floods, heat waves, landslides, rock } \\
\text { fall, wall and barriers fall, } \\
\text { thunderstorms, wind storms, fog, } \\
\text { falling trees and drowning }\end{array}$ & $\begin{array}{l}\text { Cold waves, drought, earthquakes, } \\
\text { floods, heat waves, mass } \\
\text { movements and wind storms }\end{array}$ \\
Technological & $\begin{array}{l}\text { Accidents involving farm and } \\
\text { forestry machinery, aviation } \\
\text { accidents, traffic accidents, urban } \\
\text { fires, spillage of hazardous } \\
\text { substances, industrial accidents and } \\
\text { petrol station fires, collapsing } \\
\text { buildings, domestic gas explosions, } \\
\text { pyrotechnic explosions, } \\
\text { contamination of rivers and soil, } \\
\text { contamination of wells and springs, } \\
\text { food contamination, power failures } \\
\text { and water shortages } \\
\text { marban fires } \\
\text { Cave and mine collapse and forest } \\
\text { fires }\end{array}$ \\
\hline
\end{tabular}


includes susceptibility, exposed elements and location of risk, the latter resulting from the overlay of the two previous components.

Susceptibility is the predisposition of an area to be affected by a particular hazard, according to the predisposing factors that favour its occurrence, but does not consider the probability of occurrence (Crosier and Glade 2005). The methodology for susceptibility assessment was defined for each hazardous process according to its typology. This means that multiple approaches were applied, with an emphasis on the heuristic approach and physical modelling, which were then validated with data collected from fieldwork and historical and statistical records (Guzzetti et al. 2006). The presentation of the risk component mapping outputs (Section 5.2) is supported by a more detailed description of the two methodological approaches.

According to the type of hazardous process, two approaches were developed to characterise the exposed elements. The first was applied to the less ubiquitous, more localised processes, such as floods and mass movements. In these types of hazardous process, the exposed elements included the perimeter of built-up areas, roads, critical and strategic lifelines and utilities - e.g. water catchment, petrol stations, grocery stores, the telecommunications central exchange, the municipal and regional road networks and health, justice, security and social facilities. The second approach was used for the more extensive hazardous processes, such as earthquakes, heat waves and cold waves, using census data on demographics and building characteristics broken down into the smallest statistical unit (sub-section). Building-related variables from the 2001 Census were used, including total density, density of buildings with more than two floors, density of buildings with a concrete structure and density of buildings constructed before 1960. The demographic-related variables included population density, the population aged under 5 and the population aged over 65 .

The methodology for assessing and mapping social vulnerability was based on Cutter et al. (2003), including the new approach provided by Mendes et al. (2009, Chapter 62) that considers social vulnerability as the product of criticality and support capacity. Criticality can be defined as the set of characteristics in individual and community behaviour that prevent or limit reactions in a catastrophe or disaster situation. Support capacity represents the set of infrastructures and equipment that allows for a response in catastrophe or disaster situation. Lifelines and utilities available data expressing the response capacity was accounted, such as the road network density, the number of chemist's per 1000 inhabitants and the number of firemen per 1000 inhabitants.

Finally, location of risk was expressed as the intersection of susceptibility and exposed elements. The following hazardous processes were mapped: earthquakes, mass movements, heat waves, cold waves, forest fires, urban fires, floods and traffic accidents.

\subsection{Judgement for the risk management and political engagement}

This stage involved linking the top-down land-use planning and risk management instruments to the local context.

A thorough evaluation was undertaken of the planning instruments and regulations in force for the various scales - local, regional and national - and activity sectors. These relationships considered the national strategic guidelines, planning frameworks and other specific legal regulations. A diagram highlighting 
the relationships and links between the instruments and regulations was designed and presented to the planners and managers involved.

The degree of conformity between the specific regulations for regional and municipal risk management and previous hazard assessments and identification of exposure was determined. A meeting was then held with the head of political planning and risk management (the local mayor), the civil protection operational manager, the forest fire defence manager and the academic facilitators. To support the evaluation, a grid was created which identified the multirisk and specific risk planning. The selected support capabilities and human resources were identified and financial resources were requested to build the appropriate local emergency framework. An application was submitted for European Union funding from the European Regional Development Fund, via the Portuguese Operational Programme for Central Portugal under the National Strategic Reference Frameworks 20072013, and was approved.

Using a bottom-up model, a proposal for the composition of the Municipal Commission for Civil Protection (hereinafter referred to as the MCCP or 'the Commission') was presented and discussed with the stakeholders. Using the same approach, a Municipal Service for Civil Protection (hereinafter referred to as the MSCP or 'the Service') was designed, which required stakeholder consensus and compliance with the legal framework. The Commission was assigned the political and strategic functions for civil protection, whereas the mission of the Service was to ensure operational coordination between stakeholders.

\subsection{Emergency risk planning}

A Municipal Emergency Plan for Civil Protection (hereinafter referred to as the MEPCP or 'the emergency plan') was constructed, based on a top-down approach to emergency and risk planning. This process followed the legal framework consisting of the Base Law for Civil Protection (Law 27/2006), Decree 134/2006 establishing the Integrated System for Relief Operation (SIOPS), Law 65/2007 establishing the institutional and operational framework for municipal-level civil protection, and Resolution 25/2008 establishing the regulations for the elaboration and implementation of emergency civil protection plans.

On the basis of this legal framework, the ANPC prepared the technical specifications (ANPC 2008) for the implementation and functioning of the emergency plan. In this document, the plan structure is presented as follows: (1) context of the plan, (2) organisation of the emergency response, (3) resources and agent emergency actions and (4) complementary information.

\subsection{Decision-making for the emergency planning support and coordination, public information and reassessment of governance}

The mechanisms of the decision-making processes contained in the municipal risk governance model assume that both Commission and Service for Civil Protection play a key role. Since technical guidance for training and for implementing the emergency response had been defined, stakeholder involvement was assured. Certain outputs were created to disseminate the emergency planning tools. Using a bottom-up approach, a sensitisation process was designed focusing in particular on groups at risk and local hazardous processes. As part of the emergency plan, 
cartographic outputs for risk components were linked to the land-use master planning framework.

The reassessment process included monitoring the plan, training exercises and the re-evaluation of social concerns, resources and emerging new risks.

\section{Results}

This section presents the outputs obtained during the implementation of the risk governance model described in the previous section.

\subsection{Risk appraisal}

The risk appraisal resulted in a thorough knowledge of the local geography. Figure 3 illustrates the physical and human components of this knowledge, which were crucial to the upcoming model phases. In terms of geology and tectonics, Figure 3 (a) reveals the contrast between the Meso-Cenozoic and the Hesperian Massif geological substratum translated, for instance, into distinct seismic susceptibility. The knowledge of land uses helps locate and preview the types of hazardous occurrences that may affect a given place (Figure 3(b)).

Regarding the population, a parameter combining population density, population aged under 5 and population aged over 65 represents the patterns of population exposition to risks (Figure 3(c)). A similar method was applied to characterise residential buildings, considering its density, age and construction materials (Figure 3 (d)) and critical infrastructures.

Historical records from the local newspaper highlight casualties associated with farm and forestry machinery, urban fires, traffic accidents, forest fires and wind storms. Statistical data from the District Command for Civil Protection Operations (CDOS-Leiria) and the security forces show that the majority of emergency requests were related to wind storms, traffic accidents, forest and urban fires and floods. The historical and statistical data were then compared with the responses from the survey, which included an exhaustive list of hazardous processes - natural, technological and environmental - whose severity and probability were evaluated by the stakeholder and citizen respondents. From this survey, forest fires were by far indicated as the most severe natural hazard that the municipality faced and will face in the future. Cross-referencing these data-sets resulted in a list of the 11 most relevant hazardous processes (Table 1).

\subsection{Risk characterisation}

\subsubsection{Risk classification and hierarchy}

The OEM matrix (OEM-HAM) highlights forest fires, heat waves and cold waves as hazardous processes, whereas the ANPC risk matrix highlights forest fires and traffic accidents. The combination of both enabled the major hazardous processes to be identified, as shown in Figure 4. These processes represent a significant level of severity in relation to (a) the affected population, causing fatalities and injuries, (b) the environment, particularly forest fires and (c) socio-economic activities, since they affect the various age groups and daily activity indiscriminately. The OEM-HAM attributes its highest WF to the 'MT' component (cf. Equation (1)), and distinguishes between risks that affect people and property in small percentages 


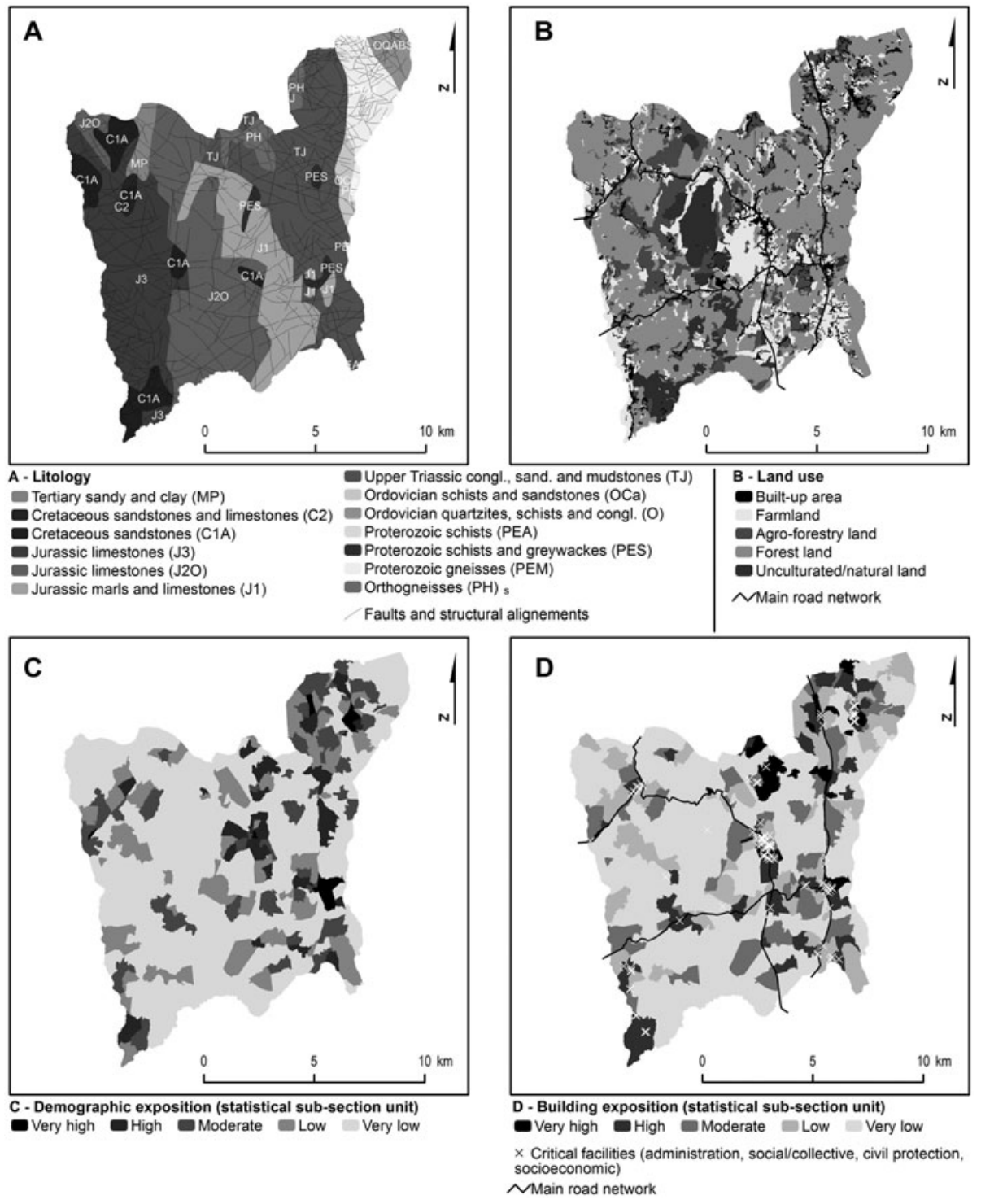

Figure 3. Examples of geographical knowledge produced: geology and tectonics (a), land use and road network (b), population patterns (c) and building characteristics and critical infrastructures (d).

(less than 5\%) and the remaining risks (OEM 2008). This helps to explain why the OEM-HAM undervalues some localised risks - e.g. traffic accidents - in comparison with the ANPC risk matrix, and highlights the more extensive ones, such as the earthquake risk, ranked 4th in the OEM-HAM and a 'moderate' risk in the ANPC matrix.

Hazardous processes classified as extreme and high risk present one or both of the following characteristics: high ubiquity and a high potential to cause fatalities, associated with a high probability of occurrence. 


\begin{tabular}{|c|c|c|c|c|}
\hline \multirow{3}{*}{ Hazard } & \multicolumn{2}{|c|}{ ANPC Risk Matrix } & \multicolumn{2}{|c|}{ ОЕМ-НАМ } \\
\hline & Probability & Class & Total & Rank \\
\hline & Severity & Class & Score & Kank \\
\hline \multirow{2}{*}{ Wind storms } & Medium-high & \multirow{2}{*}{ High } & \multirow{2}{*}{145} & \multirow{2}{*}{6} \\
\hline & Moderate & & & \\
\hline \multirow{2}{*}{ Heat waves } & Medium-high & \multirow{2}{*}{ High } & \multirow{2}{*}{197} & \multirow{2}{*}{2} \\
\hline & Accentuated & & & \\
\hline \multirow{2}{*}{ Cold waves } & Medium-high & \multirow[b]{2}{*}{ High } & \multirow[b]{2}{*}{197} & \multirow[b]{2}{*}{2} \\
\hline & Accentuated & & & \\
\hline \multirow{2}{*}{ Floods } & Medium & \multirow{2}{*}{ Moderate } & \multirow{2}{*}{133} & \multirow{2}{*}{7} \\
\hline & Low & & & \\
\hline \multirow{2}{*}{ Drought } & Medium-high & \multirow{2}{*}{ Moderate } & \multirow{2}{*}{156} & \multirow{2}{*}{5} \\
\hline & Low & & & \\
\hline \multirow{2}{*}{ Earthquakes } & Medium & \multirow{2}{*}{ Moderate } & \multirow{2}{*}{163} & \multirow{2}{*}{4} \\
\hline & Moderate & & & \\
\hline \multirow{2}{*}{$\begin{array}{l}\text { Landslides and other slope mass } \\
\text { movements }\end{array}$} & Medium-high & \multirow{2}{*}{ Moderate } & \multirow{2}{*}{88} & \multirow{2}{*}{10} \\
\hline & Low & & & \\
\hline \multirow{2}{*}{ Traffic accidents } & High & \multirow{2}{*}{ Extreme } & \multirow{2}{*}{125} & \\
\hline & Accentuated & & & 9 \\
\hline Accidents involving farm and & Medium-high & High & 87 & 11 \\
\hline forestry machinery & Accentuated & High & 87 & 11 \\
\hline & Medium-high & High & 133 & 7 \\
\hline Urban fires & Moderate & HIgn & 130 & $f$ \\
\hline Forest fires & High & Extreme & 215 & 1 \\
\hline & Accentuated & Extreme & & \\
\hline
\end{tabular}

Figure 4. Comparative results of the ANPC and OEM-HAM risk matrices.

\subsubsection{Mapping the risk components}

Figure 5 illustrates some examples of the methodologies applied in risk assessment - with regard to some of the previously identified hazardous processes - and social vulnerability. A detailed description is provided for the mass movement risk, specifically the risk of rockfall (Figure 5(a)), as an example of the advantages of the multiple method approach to assessing susceptibility. Both a heuristic method, which weights the predisposing factors, and a three-dimensional model, using the ArcGIS extension Rockfall Analyst (Lan, Martin, and Lim 2007), were applied (Santos and Tavares 2010). The predisposing factors considered were slope, lithological characteristics, fault density and land use. The weighting for each factor was refined using field verification. The $3 \mathrm{D}$ modelling input data consisted of a DTM, seeder areas - which identify the locations where the movement begins and surface properties, namely friction angle, coefficient of normal restitution and coefficient of tangential restitution, which characterise the factors influencing the onset and trajectory of the movement. The final mapping of rockfall susceptibility resulted from overlapping the higher susceptibility heuristic classes and the block projection areas produced with 3D modelling, enabling hazard areas that sometimes do not emerge in the heuristic map to be identified, such as valley bottoms. By overlaying this data with the elements at risk, a map of the location of risk is produced to assist in the allocation of technical resources to prevent future damage.

Figure 5(b) refers to the earthquake risk assessment, in which built-up areas, road networks and critical buildings are differentiated on the basis of their location 

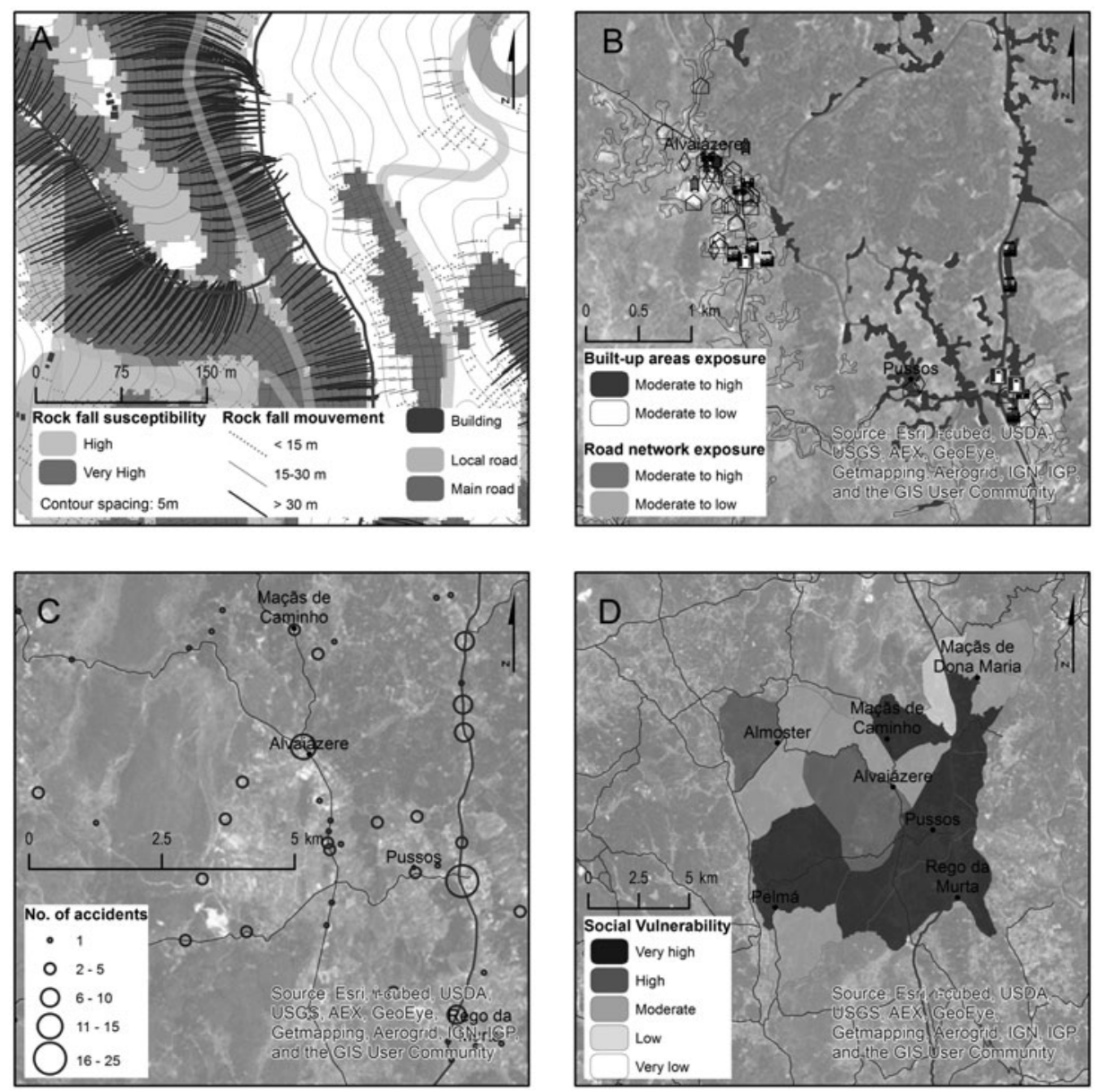

Figure 5. Examples of mapping outputs: rockfall susceptibility and exposed elements (a), built-up areas and road network exposure to seismicity (b), traffic accident susceptibility (c) and social vulnerability (d).

in relation to seismic susceptibility. Susceptibility was estimated by weighting Mercalli seismic intensity (IM 1996), lithology, and the density of faults and structural alignments. Figure 5(c) identifies the location and density of traffic accidents for the period 2000-2010, showing that Alvaiázere village, and some segments and nodes of National Road 110 are the main accident hotspots.

With regard to social vulnerability (Figure 5(d)), the variables used refer to the 2001 Census and express population characteristics (age group, family structure, education, employment and income), infrastructures (including year of construction, number of floors, building materials and water and electricity supplies) and response in emergency situations, such as the density of chemists and fire-fighters per 1000 inhabitants. These variables were collected and input for another seven geographically differing municipalities in central Portugal in order to assess social vulnerability in Alvaiázere more effectively within the regional context. One of the outputs obtained was the principal component analysis components that explain the total variance of the variables. In terms of criticality, it was observed that four 


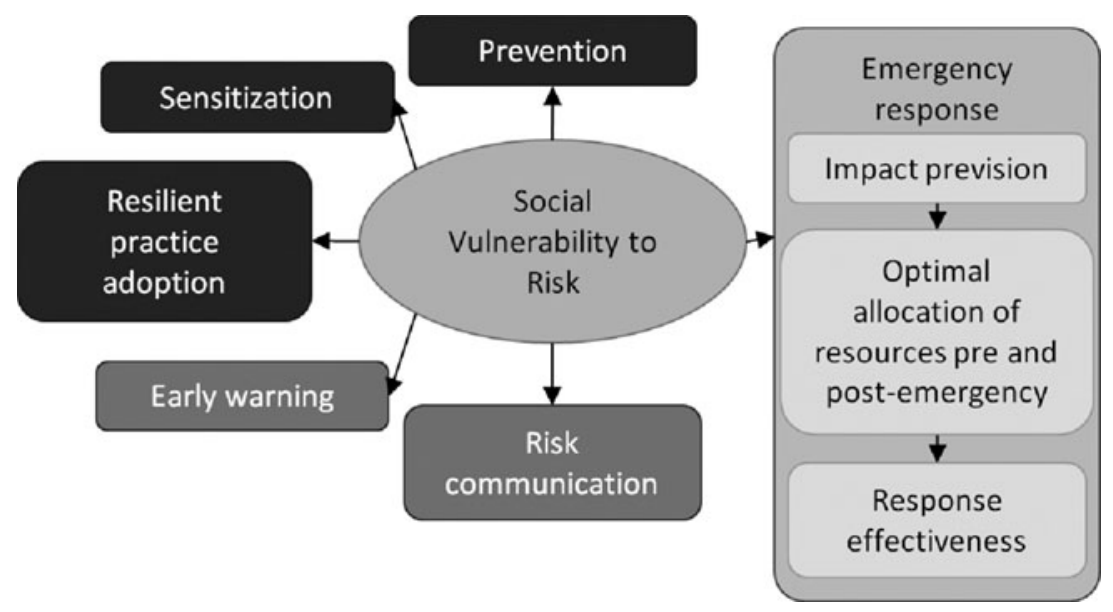

Figure 6. Applications for social vulnerability data.

components explain $58.8 \%$ of the total variance, emphasising the socio-economic and demographic structure and housing conditions. With regard to support capacity, $55.5 \%$ of the total variance is explained by four components, highlighting socio-economic structure, age of buildings and employment.

Figure 5(d) shows social vulnerability calculated at statistical section level (the disaggregation unit between the parish and statistical subsections). The general social vulnerability is high in comparison with other municipalities in the region, due to the ageing population, low levels of education and old housing (Santos et al. 2012). Among the various aspects of local emergency planning and risk governance for which the social vulnerability data are relevant (Figure 6), the data are being applied to (a) planning sensitisation and risk communication in each parish, specifically targeting the elderly and student population, (b) defining early warning operations in the event of heat and cold wave events and (c) planning the allocation of resources.

\subsection{Judgement for the risk management and political engagement}

One of the first actions undertaken at this stage was to analyse the relationship between the various levels of planning instruments and regulations in force in the various scales (Figure 7). This diagram represents the complex relationship between these related risk management elements in Portugal. It reflects the constraints involved in coordinating top-down instruments with local resources and practices. The instruments with strategic orientations reflect top-down logics that affect several partial aspects of spatial planning. The regional planning instruments imply more concise guidelines for risk governance measures on a municipal scale, influencing strategies at local level. However, local risk-related stakeholders interact solely at municipal operational level in the interactions established between health, education, land use and conservation planning instruments, and through specific risk management plans such as the PMDFCI for forest fires.

On the basis of the risk assessment data, the forest fire risk merited a special emergency plan, whereas the remaining risks were treated using a multirisk approach. This solution is supported by the results of the structured survey applied 
to 24 stakeholder representatives, who evidenced as major risk problems in the municipality the need to improve forest fire prevention with such measures as forest cleaning and selective clearing, high density of forest roads and more fire-fighting resources.

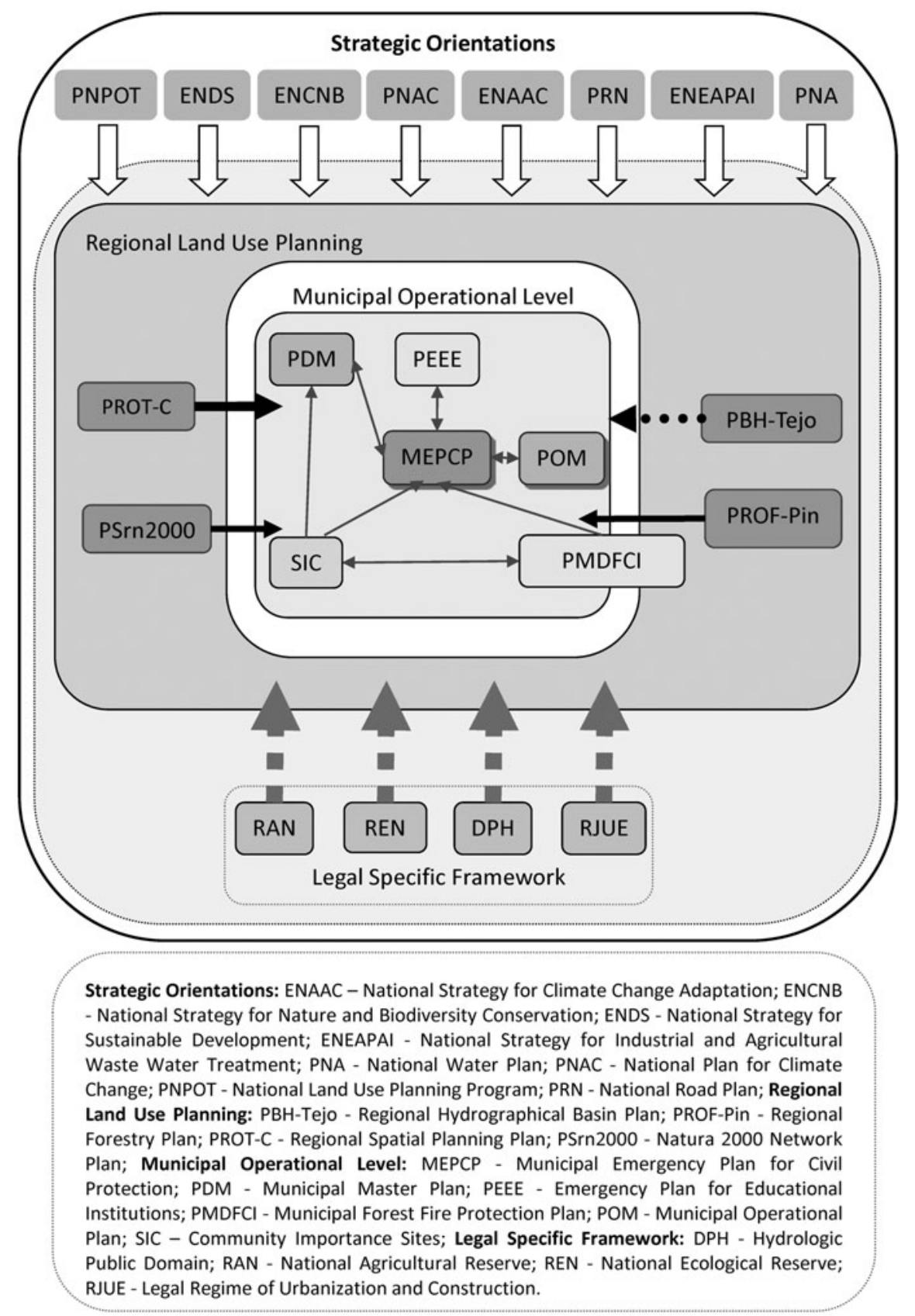

Figure 7. Interaction between planning instruments and regulations and the local risk governance framework. 
In fact, the legal framework for civil protection envisages the possibility of producing special emergency plans for certain type of risks, usually those involving earthquakes, flooding and forest fires.

The decision-making process for the composition of the Commission was a thorough one, resulting in the following composition: the municipal president (the director of the municipal emergency plan and the highest municipal political authority in civil protection), one representative of the fire department, one representative of the police department, the director of the local hospital, the director of the municipal health centre, the municipal health delegate, a representative of the local social services department and a representative of the Alvaiázere forestry producers.

On an operational level, the MSCP was created to act in several domains mitigation, emergency and post-emergency - by putting the strategies defined by the Commission into practice. The Service is composed only of municipal staff from three departments: the Quality, Safety and Environment Service, the Forestry Service and the Administrative Section. Its competences include preparing the municipal emergency plan, the execution and/or coordination of mitigation activities (e.g. exercises, simulacrums, community-orientated preventive actions, production of printed and online sensitisation materials), logistics (inventory, networking and coordination) and support for the affected population.

\subsection{Emergency risk planning}

The assessment conducted during the risk appraisal stage - including the risk assessment and concern assessment - was incorporated into the actions and strategies defined in the municipal emergency plan, which represents a significant output for the management sphere of the risk governance model. Coordinated by the Municipal Service, with guidelines emanating from the Commission and academic support, the municipal emergency plan was founded on the contributions of civil protection, health, security and business stakeholders. The MEPCP must be revised every 2 years or whenever demanded by major risk scenario changes.

After completion by the MSCP, the emergency plan was submitted to the Commission, who approved it and sent it to the up-level district civil protection authority (CDOS-Leiria). This entity submits a report to the National Commission for Civil Protection, which then approves the municipal emergency plan for a maximum period of two years, after which a review is mandatory.

The emergency plan indicates 'who is responsible for doing what' during the emergency and post-emergency phases. Its main objectives are:

- to provide the conditions and means necessary to minimise the adverse effects (loss of lives and property) of a serious accident or disaster and to restore, as soon as possible, the minimum conditions of normality;

- to establish guidelines and the management chain for the procedures carried out by the various stakeholders, services and facilities engaged in civil protection operations;

- to enable the stakeholders involved in the plan to maintain the necessary preparedness to manage major accidents or disasters;

- to provide information for the public by raising awareness, with a view to making citizens prepared, and fostering a culture of self-protection; and

- to catalogue the available means and resources. 
It is assumed that although this is a municipal plan, it requires the intervention of supra-municipal coordination bodies not only for its approval but also for its management, in both political and operational domains. Regarding the operational domain, supra-municipal intervention is foreseen in the event of actual or predicted catastrophic events. The interrelationships between the different coordination levels are defined in the SIOPS framework.

The links between the emergency plan and the stakeholders associated with civil protection are presented in Figure 8. Its structure and content guidelines are defined in Resolution 25/2008 and thoroughly detailed in ANPC (2008), in four parts: (1) context of the plan, considering, amongst other aspects, its articulation with other land use and sector plans and the criteria for activating the plan, (2) organisation of the emergency response, describing each stakeholder's mission, (3) resources and agent emergency actions in key areas of intervention and (4) complementary information in four sections, some containing confidential data on resources, risk characterisation and scenarios.

As Figure 8 illustrates, the start-up of both the Commission and the Service in the first stages of the risk governance process is assumed to be crucial to the proper functioning of the municipal emergency plan. In fact, the main objectives of the MCCP are closely related to this, namely:

- preparing the emergency plan, submitting it to the ANPC for approval and monitoring its implementation;

- monitoring other public policies linked to the civil protection system (e.g. land-use planning policies cited in the Master Plan);

- determining the activation of the emergency plan, as appropriate, in the real or likely occurrence of an hazardous event; and

- ensuring that the entities and institutions represented in the Commission can initiate the means for developing civil protection measures at municipal level.

\subsection{Decision-making involving emergency planning support and coordination, public communication and reassessment of governance}

\subsubsection{Stakeholder involvement in the decision-making process}

The relevance of defining a communication strategy became evident as the emergency plan was elaborated, and both the civil protection Commission and Service were defined. As previously mentioned, communication is understood here in a broader sense. In this regard, involvement and communication are undertaken on two levels:

- vertical communication between municipal-level civil protection stakeholders (the Commission and the Service) and district and national-level civil protection administrators. Some regular communication tools are well defined in legal instruments and refer to emergency activities associated with staff training and preparedness, articulation of planning instruments, and updating and monitoring them. Others acquire an extraordinary character, such as those applicable in emergency response actions; 


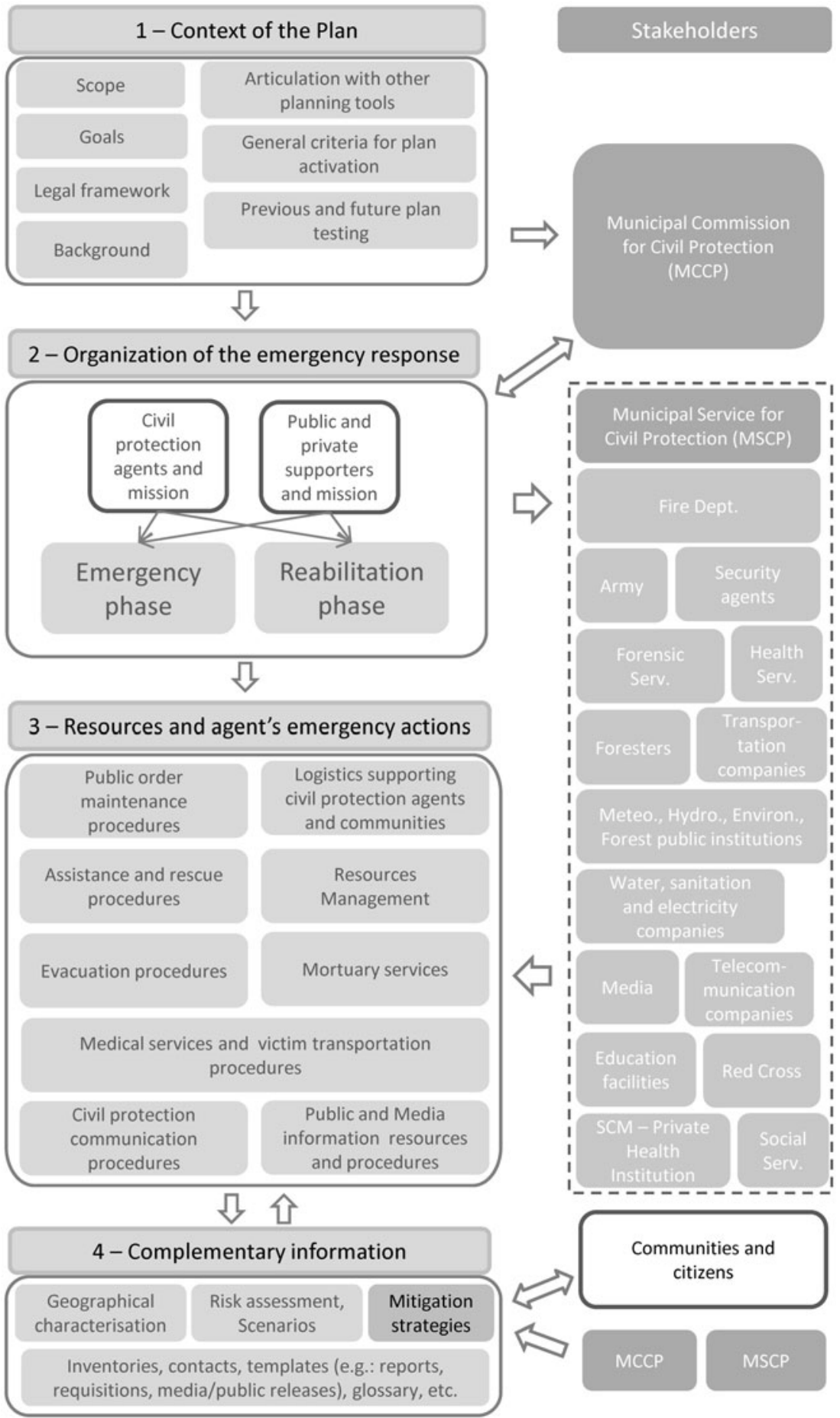

Figure 8. Relationship between the emergency plan and stakeholders involved in civil protection. 
- horizontal communication. At this level, communication includes (1) ordinary and extraordinary Commission meetings, (2) meetings regarding the day-today Service workflow, (3) civil protection issues, involving the two entities and local private and public stakeholders (e.g. the hospital, timber producers, farmers and industrialists) which arise occasionally or are planned on a regular basis (e.g. regular meetings with the fire and police departments, health, education and social services entities for monitoring and consultation).

On a local scale, regular communication between public and private stakeholders was considered vital. This also involves updating the contacts of private entities that can provide materials, equipment, facilities and skilled personal in pre-emergency, emergency and post-emergency scenarios. In addition to monitoring and consultation, this is relevant to updating the existing civil protection inventory (heavy machinery, etc.).

\subsubsection{Public communication}

This component of the strategy links communication between municipal civil protection stakeholders and communities. Materials have been produced, including a poster with the location of every parish assembly point and an explanation of the situations in which they should be used (Figure 9(b)), a self-protection guide (Figure 9(c)), signage for identifying the family gathering point (Figure 9(d)) and a web-based platform for young people containing information about the municipal risk status and self-protection measures, and demystifying some fears and incorrect procedures associated with natural, environmental and technological disasters (Figure 9(a)). A public session was organised by the Service, in which the emergency plan was discussed and the web-based platform was launched. The Service maintains regular visits to schools in which the municipality is presented to students, in its aspects of natural and human features that cause and/or are affected by natural and technological hazards.

\subsubsection{Reassessment of governance}

The reassessment stage is a logical step in this model, which is characterised by the cyclicity of its stages. It is a phase that reveals the benefits and gaps in the municipal emergency plan and re assesses it according to emerging and changing risk patterns and social concerns, as well as political and regulatory forces. Risk reassessment involves considering major changes in land use and territorial dynamics caused, for example, by the construction of a new regional highway, the abandonment of farmland and the consequences of past forest fires. A reassessment of social vulnerability is also in progress, taking into account the new data provided by the 2011 Census. As for the concerns reassessment, the Service is planning a second survey to stakeholders and a new survey is already being applied to +200 inhabitants with the objective of to understand the population risk perception, preparedness levels (insurance, goods storage, etc.) and to understand how the civil protection stakeholders' activity is perceived.

Partial and global simulacrums and command exercises were applied, which included all the stakeholders involved. The Live Exercise, which is designed to simulate the emergency response in the case of a given disaster scenario, and 


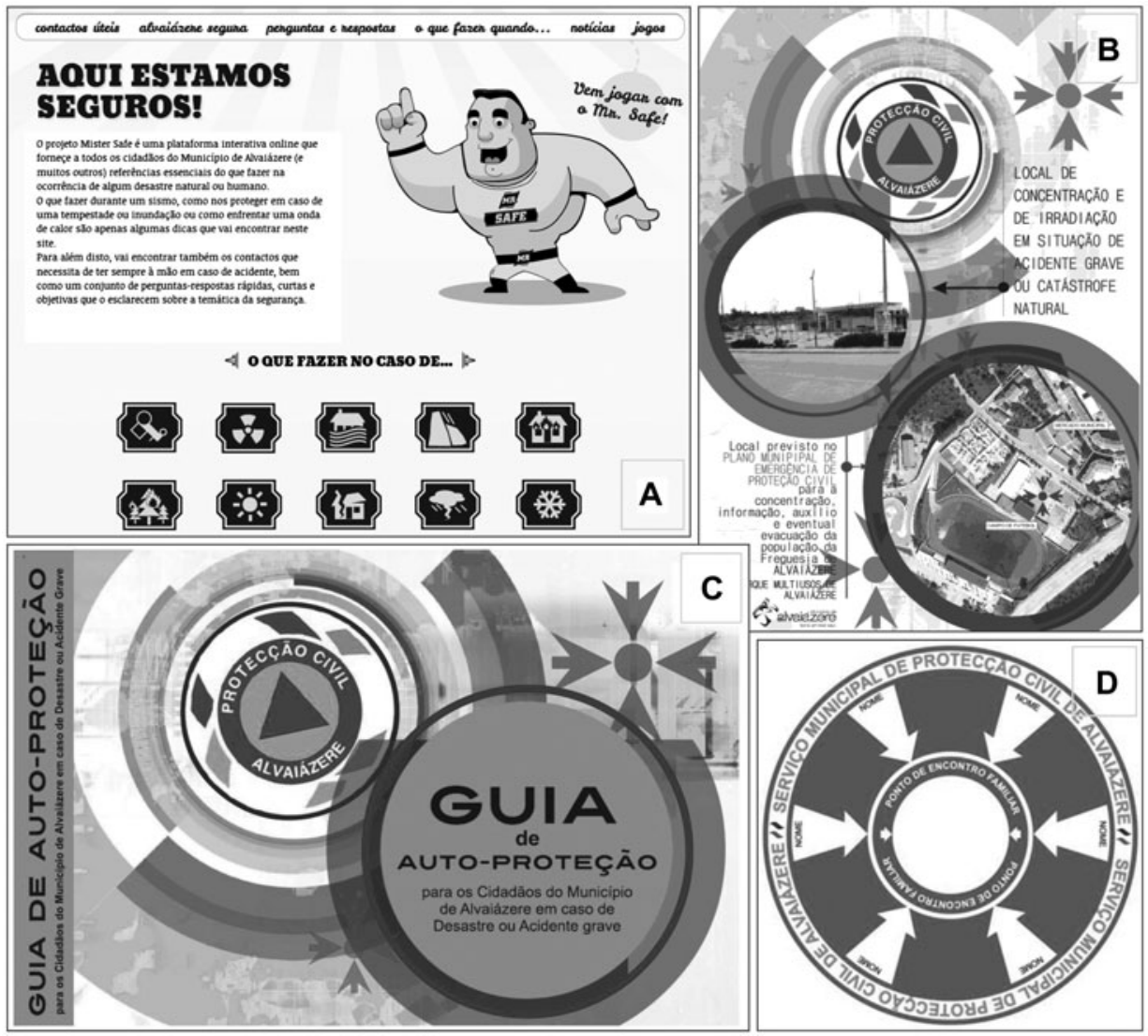

Figure 9. Web-based platform for risk sensitisation (a), poster for information on public assembly points (b), hazard self-protection guide (c) and signage for identifying family gathering point (d).

Command Post Exercise, which aims to simulate the command chain and communication tools, are relevant to the consolidation of the procedures defined in the municipal emergency plan. They were held in 2011 and 2012, and demonstrated that the current civil protection configuration is adequate and provides a good response in an emergency event. Stakeholders, mainly from the public sector but also from the private sector, demonstrated a high level of engagement and preparedness in the emergency response at municipal level.

\section{Discussion}

The initiated model is an adaptive and integrated model for risk governance in which the available resources and communication strategies, as well as the involvement of the stakeholders, are set up to ensure that the risk appraisal and emergency planning processes could be recognised and accepted by citizens and stakeholders, as proposed by Klinke and Renn (2012).

The analysis demonstrates how local government responsibilities can be understood as the key to mitigation capacity, as proposed by Measham and others 
(2011), and also to promoting changes in planning frameworks, as advocated by Corfee-Morlot et al. (2011). This can be seen as the result of ongoing work on community involvement, local experiences and resources valuation - rather than an assumed precondition - representing the different levels of participation and decision-making (Aven and Renn 2010). In other words, preformatted management solutions derived from national civil protection stakeholders were adapted to the local physical, social and institutional context.

In fact, the relevance of a valid scale analysis selection, as pointed out by Cash et al. (2006) and Fekete et al. (2010), makes effective hazard classification and characterisation possible. At the same time, the concerns and social vulnerability assessment proved crucial to the upcoming stages of the risk governance model which are aimed at interpreting both the biogeophysical and socio-economic framework, as suggested by Birkmann (2007). The tools applied are used widely in risk assessment and monitoring on a local scale (e.g. Strömgren and Andersson 2010), which is decisive in determining the most efficient allocation of resources in the management stage. In this regard, local civil protection stakeholders found risk location maps helpful in assigning resources adequately - e.g. infrastructures, sensitisation materials, evacuation corridors and prevention campaigns. As far as land use and urban planning are concerned, the appraisal will enable more appropriate regulations and strategies to be designed, such as urban trace, construction materials, building techniques and road design.

The model also balances an understanding of prevention and reduction measures with emergency response, making both part of the general decision-making process and using interlinked communications tools, thus reframing the ideas of Somers and Svara (2009) and Sapountzaki and others (2011). An example of this is the survey applied for the concern assessment, pointing out the need to improve prevention and preparedness about the risk of forest fires, which is in line with the prevailing top-down vision of regional and national administrators.

Following the regulatory norms emanating from national and regional administrators, locally adapted risk management outputs were produced, of which the process for creating the MCCP is a good example. It ended up with 11 of the university team's initial proposal of 18 stakeholders - mainly from the public sector - which local authorities think is more appropriate for the local risk context and disaster scenarios, and allows for a suitable level of operational readiness. Nevertheless, there is some uncertainty regarding the effectiveness of this structure in addressing political and strategic risk governance issues, given the absence from the Commission of several local stakeholders from the private sector. In a critical situation, this may result in a strategy that is non-comprehensive to citizens, underlining certain weaknesses in its legitimacy, as mentioned by Moar (2010).

The structure of the MSCP was the subject of a valuable discussion regarding its composition and functioning. The municipality decided that it was not financially sustainable to create a new municipal service with its own staff and facilities, and the solution was therefore to incorporate three existing departments (cf. Section 5.3), which was assumed to be adequate for the coordination, logistics and planning tasks assigned to the Service in a municipality with a population of less than 8000 inhabitants. Moreover, the existing Forestry Service was already responsible for these tasks in one of the most important local hazardous processes, namely forest fires. This option may lead to some future overlapping of competences and conflicts of responsibility for decision-making, as described by Liu and others (2011) and 
Measham and others (2011), and may affect consistent risk management in periods with fewer hazardous events, as suggested by Somers and Svara (2009). However, the balance in terms of commitment is the result of the current limited resources in a municipality of this size.

All the stakeholders involved considered that the municipal emergency plan represented an advance on the emergency and post-emergency response at local level. Its elaboration process underlined the relevance of cross-scale and cross-level interactions in risk management and their pervasiveness, as noted by Cash et al. (2006). Although Portuguese legislation on civil protection at municipal level has emerged from a top-down approach, the Alvaiázere experience shows that strategies are better defined on a local basis. This is valid both for prevention and preparedness strategies as well as emergency response strategies, and has overcome the difficulties highlighted by Sapountzaki and others (2011).

Stakeholder involvement and communication are fundamental elements in the decision-making process. In fact, it may be considered that the outputs achieved in this area contribute significantly to establishing a local community-based strategy which has the potential to grow naturally into more advanced forms of stakeholder and public involvement.

The assumed central role of communication in the risk governance model was the key to success in every stage of its development, allowing for the involvement of non-civil protection stakeholders, who introduced knowledge, practices and values from a social, environmental and economic point of view, breaking down barriers and administrative hierarchies, as shown by Parker, Tapsell, and McCarthy (2007), Aven and Renn (2010) and Klinke and Renn (2012).

\section{Conclusions}

Our research describes the components of a municipal-level risk governance process that can be applied in different sociocultural and geographical contexts. The interconnected aspects are the application of tools for hazard and concerns assessment, the building of a local risk governance platform for municipal civil protection, the implementation of the municipal emergency plan, stakeholder involvement and communication with the public. The study has a broad framework, involving procedural mechanisms, institutional commitments and citizen and stakeholder involvement.

The analysis shows the importance of the local scale as the best way to establish good risk assessment and better management of the emergency system. This rescaling of the governance of risk enables local specificities - resulting from hazardous processes - to be included, as well as social vulnerability. Science for policy is not free from uncertainty and therefore incorporating stakeholder knowledge into the risk appraisal process signified increased trust in future risk management options.

It demonstrates how mitigation strategies - not restricted to the emergency planning framework but also involving urban and environmental planning, preventive healthcare, social care facilities and building regulation, among other factors - can be addressed in a risk planning framework, in a transparent model that involves the participation of all stakeholders. This reflects a comprehensive procedural mechanism, as identified by Aven and Renn (2010). 
The model in place shows that even at local level it is possible to link top-down rules and guidelines with local resources and expectations to create a bottom-up frame that is efficient and recognised as such by the different stakeholders involved in multilevel risk governance on a local and non-local level (van Asselt and Renn 2011).

The study also demonstrates that a governance model focusing on risk communication and the involvement of citizens and stakeholders requires the inclusion of different types of knowledge and practices, mobilisation and involvement in the different phases of risk management, recognition and acceptance of planning, and confidence in emergency management. This is part of a communitybased strategy, as noted by Klinke and Renn (2012), and incorporates the complex cultural dynamics of constructing risk issues in terms of political, economic, legal and administrative sociologics, as emphasised by Boholm, Corvellec, and Karlsson (2012).

The construction of the model also demonstrates the ability to establish effective governance at local level that involves risk beyond the prevention and mitigation of natural and technological hazardous events, as well as emergency management, linking objectives and reconciling stakeholder positions. It thus demonstrates the ability to move beyond mitigation, as stressed by the Measham and others (2011), and the capacity to overcome inconsistencies in public policies for risk management (Sapountzaki et al. 2011).

In conclusion, it may be said that integrated risk management at local level is the best way to achieve a governance practice that is recognised by citizens and fosters resilient communities.

\section{Acknowledgements}

This work is funded by National Funds through FCT - Foundation for Science and Technology under the project 'DISASTER - GIS database on hydro-geomorphologic disasters in Portugal: a tool for environmental management and emergency planning (PTDC/ CS-GEO/103231/2008)'.

\section{References}

Adger, W. N. 2000. "Social and Ecological Resilience: Are They Related?" Progress in Human Geography 24: 347-364.

ANPC. 2008. Manual de apoio à elaboração e operacionalização de planos de emergência de protecção civil [Handbook to Support the Preparation and Operation of Civil Protection Emergency Plans], Technical specification notebook \#3. Lisbon: Autoridade Nacional da Protecção Civil.

ANPC. 2009. Guia para a caracterização de risco no âmbito da elaboração de planos de emergência de protecção civil [Handbook to Support Risk Characterization under the Preparation of Civil Protection Emergency Plans], Technical specification notebook \#9. Lisbon: Autoridade Nacional da Protecção Civil.

Apel, H., G. T. Aronica, H. Kreibich, and A. H. Thieken. 2009. "Flood Risk Analysis How Detailed Do We Need to Be?" Natural Hazards 48: 79-98.

Aven, T., and O. Renn. 2010. Risk Management and Governance. Concepts, Guidelines and Applications. Berlin: Springer-Verlag.

Beck, U. 1992. Risk Society: Towards a New Modernity. London: Sage.

Bhattamishra, R., and C. B. Barrett. 2010. "Community-based Risk Management Arrangements: A Review." World Development 38 (7): 923-932.

Birkmann, J. 2007. "Risk and Vulnerability Indicators at Different Scales: Applicability, Usefulness and Policies Implications." Environmental Hazards 7: 20-31. 
Boholm, A., H. Corvellec, and M. Karlsson. 2012. "The Practice of Risk Governance: Lessons from the Field." Journal of Risk Research 15 (1): 1-20.

Cash, D. W., W. Adger, F. Berkes, P. Garden, L. Lebel, P. Olsson, L. Pritchard, and O. Young. 2006. "Scale and Cross-scale Dynamics: Governance and Information in a Multilevel World." Ecology and Society 11 (2): 8. Accessed. http://www.ecologyandsociety.org/vol11/iss2/art8/

Chen, K., R. Blong, and C. Jacobson. 2003. "Towards an Integrated Approach to Natural Hazards Risk Assessment Using GIS: With Reference to Bushfires." Environmental Management 31 (4): 546-560.

Corfee-Morlot, J., I. Cochran, S. Hallegatte, and P. J. Teasdale. 2011. "Multilevel Risk Governance and Urban Adaptation Policy." Climatic Change 104 (1): 169-197.

Crosier, M., and T. Glade. 2005. "Landslide Hazard and Risk: Issue, Concepts and Approach." In Landslide Risk Assessment, edited by T. Glade, M. G. Anderson, and M. J. Crosier, 1-40. Chichester: Wiley.

Cutter, S. L., J. B. Boruff, and W. L. Shirley. 2003. "Social Vulnerability to Environmental Hazards." Social Science Quarterly 84 (2): 242-261.

EMA. 2004. Emergency Risk Management Applications Guide. Manual 5. 2nd ed. Canberra: Emergency Management Australia.

Fekete, A., M. Damm, and J. Birkmann. 2010. "Scales as a Challenge for Vulnerability Assessment." Natural Hazards 55: 729-747.

Fischer, F. 2003. Reframing Public Policy: Discursive Politics and Deliberative Practices. Oxford: Oxford University Press.

Gray, P. C. R., R. M. Stern, and M. Biocca, eds. 1998. Communicating About Risks to Environment and Health in Europe. Dordrecht: Kluwer Academic.

Flez, C., and P. Lahousse. 2004. "Recent Evolution of Natural Hazard Management Policy in France, The Example of Serre-Chevalier (French Alps)." Environmental Management 34 (3): 353-362.

Greiving, S., M. Fleischhauer, and J. Luckenkotter. 2006. "A Matrix Based Methodology for an Integrated Risk Assessment of Spatially Relevant Hazards." Journal of Environmental Planning and Management 49: 1-19.

Guzzetti, F., P. Reichenbach, F. Ardizzone, M. Cardinali, and M. Galli. 2006. "Estimating the Quality of Landslide Susceptibility Models." Geomorphology 81: 166-184.

Handmer, J., and S. Dovers, eds. 2007. Handbook of Disasters and Emergency Policies and Institutions. London: Earthscan.

Henstra, D. 2010. "Explaining Local Policy Choices: A Multiple Streams Analysis of Municipal Emergency Management." Canadian Public Administration 53: 241-258.

Höppner, C., M. Buchecker, and M. Bründl. 2010. Risk Communication and Natural Hazards. Caphaz-net WP5 Report. Davos: Swiss Federal Institute for Forest, Snow and Landscape Research (WSL) and WSL Institute for Snow and Avalanche Research.

IDEHLG. 2006. A Framework for Major Emergency Management - Working Draft. Guidance Document 1: A Guide to Risk Assessment in Major Emergency Management. Irish Department of the Environment, Heritage \& Local Government.

IM. 1996. Carta de Isossistas de Intensidade Máxima baseada na sismicidade histórica e actual [Map of Maximum Intensity Isoseismal Lines Based on Actual and Historical Seismicity] (1755-1996). Instituto de Meteorologia. 1:1.000.000. Lisbon: Instituto do Ambiente (ed.).

IRGC. 2005. Risk Governance: Towards an Integrative Approach, White Paper No. 1. Geneva: International Risk Governance Council.

Julião, R. P., F. Nery, J. L. Ribeiro, M. C. Branco, and J. L. Zêzere. 2009. Guia metodológico para a produção de cartografia municipal de risco e para a criação de sistemas de informação geográfica de base municipal [Methodological Guide for the Production of Municipal Risk Mapping and the Creation of Municipal-Based Geographic Information Systems]. Lisbon: Autoridade Nacional de Protecção Civil, Direcção-Geral do Ordenamento do Território e Desenvolvimento Urbano, Instituto Geográfico Português.

Kasperson, J. X., R. E. Kasperson, and K. Dow. 2001. "Global Environmental Risk and Society." In Global Environmental Risk, edited by J. X. Kasperson and R. E. Kasperson, 1-48. Tokyo: United Nations University Press, Earthscan. 
Klinke, A., and O. Renn. 2012. "Adaptive and Integrative Governance on Risk and Uncertainty." Journal of Risk Research 15 (3): 273-292.

Lan, H., C. D. Martin, and C. H. Lim. 2007. "RockFall Analyst: A GIS Extension for Three-dimensional and Spatially Distributed Rockfall Hazard Modelling." Computers \& Geosciences 33: 262-279.

Liu, W.-H., C.-C. Wu, H.-T. Jhan, and C.-H. Ho. 2011. "The Role of Local Government in Marine Spatial Planning and Management in Taiwan." Marine Policy 35 (2): 105-115.

Measham, T. G., B. L. Preston, T. F. Smith, C. Brooke, R. Gorddard, G. Withycombe, and C. Morrison. 2011. "Adapting to Climate Change Through Local Municipal Planning: Barriers and Challenges." Mitigation and Adaptation Strategies for Global Change 16: 889-909.

Mendes, J. M., and A. O. Tavares. 2008. "Building Resilience to Natural Hazards. Practices and Policies on Governance and Mitigation in the Central Region of Portugal." In Safety, Reliability and Risk Analysis - Theory, Methods and Applications, org., edited by S. Martorell, C. G. Soares, and J. Barnett, Vol. 2, 1577-1584. London: Taylor \& Francis Group.

Mendes, J. M., A. O. Tavares, S. Freiria, and L. Cunha. 2009. "Social Vulnerability to Natural and Technological Hazards. The Relevance of Scale." In Reliability, Risk and Safety: Theory and Applications, edited by S. G. Soares, R. Bris, and S. Martorell, Vol. 3, 445-451. London: CRC Press.

Moar, M. 2010. "The Relationship Between Intervention by Central/Federal or Local Levels of Government and Local Emergency Preparedness Training." Administration \& Society 42 (3): 315-342.

OEM. 2008. Hazard Analysis Methodology. Oregon Emergency Management. Accessed August 8,2012 . http://cms.oregon.gov/OMD/oem/docs/library/oem_hazard_analysis_methodology_5_08.pdf.

Palm, J., and E. Ramsell. 2007. "Developing Local Emergency Management by Co-ordination Between Municipalities in Policy Networks: Experiences from Sweden.” Journal of Contingencies and Crisis Management 15 (4): 173-182.

Parker, D., S. Tapsell, and S. McCarthy. 2007. "Enhancing the Human Benefits of Flood Warnings." Natural Hazards 43: 397-414.

Pelling, M., C. High, J. Dearing, and D. Smith. 2008. "Shadow Spaces for Social Learning: A Relational Understanding of Adaptive Capacity to Climate Change within Organizations." Environment and Planning A 40: 867-884.

Renn, O. 2006. "Participatory Processes for Designing Environmental Policies." Land Use Policy 23: 34-43.

Santos, P. P., and A. O. Tavares. 2010. "Modelação de processos de queda de blocos em vertentes na região de Alvaiázere: dois estudos caso [Rock Fall Modelling in the Region of Alvaiázere: Two Case Studies]." In Modelação de sistemas geológicos, edited by L. J. P. F. L. Neves, A. Pereira, C. Gomes, L. Pereira, and A. O. Tavares, 363-373. Coimbra: Laboratório de Radioactividade Natural da Universidade de Coimbra.

Santos, P. P., A. O. Tavares, L. Cunha, J. M. Mendes, and C. Leal. 2012. "Governação (ou planeamento de emergência) à escala municipal: Um caso de estudo no concelho de Alvaiázere [Risk Governance (or Emergency Planning) at the Municipal Scale: A Case Study in the Municipality of Alvaiázere]." In Riscos, segurança e sustentabilidade, edited by C. G. Soares, A. P. Teixeira, and C. Jacinto, 221-235. Lisbon: Edições Salamandra.

Sapountzaki, K., S. Wanczura, G. Casertano, S. Greiving, G. Xanthopoulos, and F. F. Ferrara. 2011. "Disconnected Policies and Actors and the Missing Role of Spatial Planning Throughout the Risk Management Cycle." Natural Hazards 59 (3): $1445-1474$.

Schmidt-Thomé, P., and K. Schmidt-Thomé. 2007. "Natural Hazards and Climate Change: Stakeholder Communication and Decision-Making Processes: An Analysis of the Outcomes of the 2006 Davos Conference on Disaster Reduction." Management of Environmental Quality: An International Journal 18 (3): 329-339.

Somers, S., and J. H. Svara. 2009. "Assessing and Managing Environmental Risk: Connecting Local Government Management with Emergency Management." Public Administration Review 69 (2): 181-193. 
Strömgren, M., and R. Andersson. 2010. "The Usage of Safety Management Tools in Swedish Municipalities." Safety Science 48: 288-295.

Tavares, A. O. 2010. "Riscos naturais e ordenamento do território - modelos, práticas e políticas públicas a partir de uma reflexão para a Região Centro de Portugal [Natural Hazards and Territory Planning - Models, Practices and Public Policies from Reasonings for the Central Region of Portugal]." Prospectiva e Planeamento 17: 33-55.

Tavares, A. O., and J. M. Mendes. 2010. "Risk Prevention, Risk Reduction and Planning Policies: Misunderstandings and Gaps in a Local Context." In Risk, Models and Applications - Selected Papers, org, edited by H. Kremers and A. Susini, 73-88. Berlin: CODATA Germany.

van Asselt, M. B. A., and O. Renn. 2011. "Risk Governance.” Journal of Risk Research 14 (4): 431-449.

Veil, S. R., R. S. Littlefield, and K. E. Rowan. 2009. "Dissemination as Success: Local Emergency Management Communication Practices." Public Relations Review 35 (4): 449-451.

Voss, M., and K. Wagner. 2010. "Learning from (Small) Disasters." Natural Hazards 55 (3): $657-669$.

Waugh, W. L. 1996. "Disaster Management for the New Millennium." In Disaster Management in the U.S. and Canada, edited by R. T. Sylves and W. L. Waugh, 344-359. Springfield, IL: Charles C. Thomas.

Weichselgartner, J., and R. E. Kasperson. 2010. "Barriers in the Science-policy-practice Interface: Toward a Knowledge-action-system in Global Environmental Change Research." Global Environmental Change 20: 266-277. 